\title{
Tobacco Product Use and Smoking Frequency Among U.S. Adults with Intellectual and Developmental Disabilities
}

\author{
Author \\ Elaine Eisenbaum, $\mathrm{PhD}, \mathrm{MSW}$ \\ The University of Texas at Austin, School of Social Work \\ 1925 San Jacinto Blvd \\ Stop D3500 \\ Austin, Texas 78712-1405 \\ USA
}

While the work was carried out at The University of Texas at Austin School of Social Work, the author now works at University of Kentucky and has the following contact information:

University of Kentucky

Human Development Institute

120 Graham Avenue

Lexington, KY 40508, USA

1-859-257-6086

eeisenbaum@uky.edu

\section{Conflict of Interest}

The author declares there is no conflict of interest.

\section{Acknowledgements}

The author wishes to acknowledge Healthy Athletes' funders. Healthy Athletes data collection was supported by cooperative agreement \#U59DD000995 from the U.S. Centers for Disease Control and Prevention and a grant from the Golisano Foundation. The author would also like to thank Dr. Diana DiNitto for her generous mentorship and helpful feedback on previous drafts.

This is the author manuscript accepted for publication and has undergone full peer review but has not been through the copyediting, typesetting, pagination and proofreading process, which may lead to differences between this version and the Version of Record. Please cite this article as doi: $10.1111 /$ jir.12507

This article is protected by copyright. All rights reserved. 


\begin{abstract}
Background: People with intellectual and developmental disabilities (IDD) have been overlooked in tobacco use research although they are likely to experience tobacco-related health disparities. This study examined tobacco product use and smoking frequency and amount among a sample of U.S. Special Olympics athletes with IDD. Methods: Multiple regression analysis was used to test whether age, gender, BMI, blood pressure, bone density, eating fruits and vegetables, and family member tobacco use were correlated with the number of cigarettes smoked per day. Results: The sample of people with IDD who used tobacco $(n=501)$ were aged 18-75 (M=33.37) and 76.4\% were male. $73.6 \%$ reported cigarette use only, $10.6 \%$ reported dual or poly use of cigarettes and other tobacco products (cigars, pipe, chewing tobacco), and 15.8\% reported using only tobacco products other than cigarettes. Men were more likely than women to use tobacco products other than cigarettes. Of the cigarette smokers, $79.6 \%$ were daily smokers, and their mean cigarettes per day (CPD) was 10.08 (SD=9.50). Special Olympics athletes who did not have low bone density, and those who consumed fruits and vegetables less than daily reported higher numbers of CPD. Conclusion: Although people with IDD are less likely to use tobacco than the general population, study results suggest that people with IDD who smoke cigarettes are just as likely as smokers in the general U.S. population to smoke daily. Improving overall health behaviours may be important in helping smokers with IDD to reduce their tobacco use. Research is needed to understand longitudinal patterns of tobacco use and how to prevent tobacco use among people with IDD.
\end{abstract}

This article is protected by copyright. All rights reserved. 


\section{Keywords: intellectual disability, developmental disability, tobacco, smoking, cigarette, health}

\section{Introduction}

Awareness of the negative health effects of tobacco use, coupled with prevention and cessation efforts, have effectively reduced daily smoking in the United States over the past five decades (Schane et al. 2010; Jamal et al. 2015). However, 25.2\% of the U.S. population continues to use tobacco (Agaku et al. 2014), and tobacco use remains one of the leading preventable causes of death in the United States (CDC 2015d).

Marginalised populations experience tobacco-related health disparities that lead to even greater risk of disease and mortality (Okuyemi et al. 2015). The Tobacco and Health Disparities (TRHD) committee, formed in 2006 as part of Society for Research on Nicotine \& Tobacco, has worked to combat tobacco-related health disparities by advancing research in this area. Since its inception, TRHD research has greatly improved the evidence-base supporting prevention and cessation efforts for a number of populations, including those of low socioeconomic status, racial and ethnic minorities, sexual minorities, and people with mental illness (Okuyemi et al. 2015). However, people with intellectual and developmental disabilities (IDD) have been overlooked in these and similar research efforts, although this population is likely disproportionately affected by tobacco-related health issues. While people with IDD are less likely to use tobacco than the general population (CDC 2015b; Havercamp \& Scott 2014; Henderson et al. 2008; Janicki et al. 
2002), tobacco use poses a considerable health risk for people with IDD because they already experience high rates of chronic diseases and health complications that are also known to be associated with tobacco use, including arthritis, asthma and other respiratory conditions, cardiovascular disease, diabetes, eye disease, low bone density, stroke, and unhealthy teeth and gums (CDC 2015c; Haveman et al. 2011; Krahn et al. 2006; Reichard et al. 2011; Special Olympics International n.d.c,; Special Olympics International 2015b; Special Olympics International Research and Evaluation Department n.d). Additionally, people with IDD have inadequate access to health care and health promotion and education programs (Campbell \& Edson 2009), depriving them of information vital to making informed decisions about health-risk behaviours such as tobacco use, and potentially exacerbating existing tobacco-related health problems.

\section{Tobacco Use Trends}

Monitoring tobacco use trends is an important component of understanding tobaccorelated health disparities. Careful monitoring of trends in the general U.S. population has revealed successes in reducing smoking and identified new trends in tobacco use that are cause for concern. While cigarette use in the United States has declined over the past five decades, other types of tobacco product use have not (Agaku et al. 2014). It is estimated that among U.S. adult tobacco users, $46.4 \%$ use cigarettes only, $33 \%$ are dual or poly product users, and $20.6 \%$ use only one tobacco product other than cigarettes. 
Tobacco use researchers are also directing attention to the rise in prevalence of nondaily cigarette use (Schane et al. 2010; Jamal et al. 2015). According to the CDC, 76.8\% of U.S. smokers are daily smokers and $23.2 \%$ are nondaily smokers (Jamal et al. 2015). Nondaily smokers are more likely to be younger, female, Black or Latino, and have higher levels of education and higher incomes than daily smokers (Jones et al. 2011; Li et al. 2015; Sacks et al. 2012; Schane et al. 2010; Schauer et al. 2014). While nondaily smokers may have lower health risks than daily smokers, the health risks of any cigarette use are substantial. Both daily and nondaily smokers have an increased risk of mortality and lower health-related quality of life compared to nonsmokers (Schane et al. 2010). Nondaily and daily smokers also report similar levels of depression, psychological distress, and substance use, all of which are higher than they are among non-smokers (Li et al. 2015).

\section{Tobacco Use Among People with IDD}

The only source of published U.S. longitudinal information on tobacco use among people with IDD is the National Core Indicators (NCI), a database consisting of representative samples of people with IDD from a number of U.S. states. However, NCI calculations of prevalence rates are inconsistent from year to year because both the number of states included and which states are included varies. NCI reported a tobacco use prevalence rate of $8 \%$ in 2008-2009 and 7\% in 2013-2014 (National Core Indicators n.d.). Another caveat in the NCI data concerns the question posed on its survey, "Does this person smoke/chew tobacco?" since it neither captures all 
tobacco users nor provides data that differentiates between those who smoke, chew tobacco, or do both. The NCI database also contains no data on tobacco use frequency.

In 1995 Rimmer et al. looked at CPD smoked among people with IDD and Burtner et al. (1995) looked at the types of tobacco products people with IDD used. Since then, smoking in the general population has changed (e.g. fewer people smoke cigarettes and the products they smoke are different), and in the last 20 years, no U.S. study has reported on the types of tobacco products adults with IDD use or the frequency with which they use. However, several studies conducted in Europe have attempted to measure the frequency of tobacco use among individuals with IDD. McGuire et al. (2007) surveyed 157 people with IDD in Ireland and found only four smokers, only one of whom smoked daily. Emerson and Turnball's 2005 study (n=95) in Great Britain found that $14 \%$ of adolescents with IDD surveyed reported smoking, with $6 \%$ of them reporting smoking $7+$ cigarettes per day. Other European studies have reported that individuals with mild levels of intellectual disability (Taylor et al. 2004) and those who are older (Haveman et al. 2011) not only smoke at greater rates but also with higher frequency than other people with IDD. Haveman et al.'s 2011 survey of adults with IDD across 14 european countries $(n=1,253)$ found that daily smoking was highest among those who were ages $65+(10.9 \%)$, and that $7.1 \%$ of this age group reported smoking more than 20 CPD. In Taylor et al.'s UK study (2004), 6.2\% of study participants $(n=435)$ reported smoking, and those with mild IDD reported the highest smoking rate $(9.3 \%)$ and the most CPD. In the United States, more research is needed to determine current tobacco use trends among people with IDD. 


\section{Health Disparities Among People with IDD}

Although life expectancy for individuals with IDD increased significantly over the $20^{\text {th }}$ century, overall life expectancy for people with IDD in the United States and other high-income countries is still roughly 20 years lower than that of the general population (Lauer \& McCallion 2015; O'Leary, Cooper \& Hughes-McCormack 2017). This discrepancy is likely due to the high rates of chronic health complications and diseases that affect people with IDD (Haveman et al. 2011; Krahn et al. 2006; Reichard et al. 2011). While some individuals with IDD who have specific genetic disorders, such as Down syndrome or Fragile X, have comorbid health conditions that result from genetic abnormalities (Berry-Kravis 2002; Freeman et al. 1998), these conditions alone do not explain the high rates of chronic health complications in this population.

Health is determined by many factors including genetics, social circumstances, environment, individual behaviour, and health care access (Krahn et al. 2006). For example, poverty and lack of appropriate health care provision are substantial contributors to poor health status and premature deaths among people with IDD (Emerson \& Hatton 2007; Heslop et al. 2014). However, historically, disability has been viewed solely from a medical lens, leading to a false conflation of disability and illness. The common assumption that poor health is attributable to disability status alone has led to illness being overlooked and under-diagnosed among people with IDD, a phenomenon known as "diagnostic overshadowing” (Krahn et al. 2006; Special Olympics International Research and Evaluation Department n.d.). Researchers and healthcare providers have overlooked the many external contributors to the poorer health of people with 
IDD compared to the general population. In order to improve health outcomes and life expectancy for people with IDD, it is important that known contributors to poor health and mortality, such as tobacco use, be examined among this population.

\section{Study Aims}

This study aimed to increase knowledge about tobacco use among people with IDD by examining types and frequency of tobacco product use among a U.S. sample of adults with IDD. The study also explored factors related to amount (quantity) of cigarette use among smokers with IDD.

\section{Methods}

Data used in this study were made available by Special Olympics International (SOI), a non-profit organization that provides sports training and competition for children and adults with IDD (Special Olympics International n.d.b). Worldwide, over 4.5 million athletes participate in Special Olympics activities, approximately 727,000 of whom are from North America (Special Olympics International n.d.a; Special Olympics International n.d.b). To be eligible to participate in Special Olympics competitions, athletes must have a diagnosis of an intellectual disability, cognitive delays, or a related developmental disability, such as autism or cerebral palsy, and be eight years of age or older (SOI 2015a).

In 1997 SOI began providing Special Olympics athletes free health screenings through their Healthy Athletes program. Since the program's inception, SOI has conducted more than 1.6 million health exams in more than 130 countries (Special Olympics International n.d.b.). Healthy 
Athletes exams take place at state, national, and international Special Olympics events. Athletes have the opportunity to visit the Healthy Athlete Village where they rotate through seven stations specific to different aspects of health-Fit Feet (podiatry), FUNfitness (physical therapy), Healthy Hearing (Audiology), MedFest (sports physical exam), Opening Eyes (vision), Special Smiles (dentistry), and Health Promotion (health and well-being). At each station, trained volunteers assess an athlete's health, and health educational information is provided to athletes.

Data for this study were collected at the Healthy Athletes Health Promotion station. The SOI research office provided data for athletes who participated in health screenings between 2007 and 2014. The data were de-identified and SOI removed duplicates by selecting at random a single year of data for each participant.

\section{Variables}

The following demographic and health indicator variables from the SOI Health Promotion database were used in this study: age (in years), gender (coded as male [0] or female [1]), systolic blood pressure (SBP), diastolic blood pressure (DBP), body mass index (BMI; calculated as weight in kilograms divided by squared height in meters), and bone density (coded in the regression analysis as low [0] or not low [1] based on the reported T-Score and the WHO definition of low bone density; NIH 2015). Lifestyle variables included family member tobacco use, coded as no (0) or yes (1) based on the question "Does someone in your family smoke or chew tobacco?", and fruit and vegetable consumption, coded based on a question that asked whether participants consumed fruits and vegetables less than daily (weekly, less than 1 serving 
per day, or never=0), or daily (more than 5 servings per day, 3-5 servings per day, or 1-2 servings per day=1). Tobacco use variables included type of tobacco product (cigarettes, cigars, chewing tobacco, and pipe), tobacco use frequency (daily or nondaily), and number of cigarettes smoked per day.

Trained volunteers assessed and recorded all health indicators (blood pressure, BMI, and bone density). Athletes self-reported other data used in this study.

\section{Analysis}

Analyses for this study were conducted using SPSS Version 23. Descriptive statistics were used to examine demographic, health, lifestyle, and tobacco use variables. To compare subsamples, chi-square tests, independent sample t-tests, and one-way ANOVA tests were used with Bonferroni corrections for multiple comparisons. Multiple regression analysis was used to test whether age, gender, BMI, blood pressure, bone density, eating fruits and vegetables daily, or family member tobacco use were associated with number of cigarettes smoked per day in the subsample that smoked cigarettes but did not use other tobacco products. For all analyses, a p value of $<.05$ was used to indicate statistical significance.

\section{Results}

\section{Sample Characteristics}

Total sample $(n=13,815)$ 
The total sample of U.S. Special Olympics athletes $(n=13,815)$ were aged 18-93 (M=32.8). Of the total sample, 13,714 athletes reported on gender; 7,834 were male (57.1\%) and 5,880 were female $(42.9 \%)$.

\section{Tobacco users (total $n$ reported $=863$ )}

Of the total sample, $6.3 \%(n=863)$ reported using tobacco and this group also ranged in age from 18-93 (M=33.7). 857 of the 863 tobacco users reported on gender; 636 were male $(74.2 \%)$ and 221 were female $(25.8 \%)$.

Type of tobacco product used (total $n$ reported $=501$ )

Of the 863 who reported using tobacco, 501 also reported the type of tobacco product they used (see Table 1). The sample reporting type of tobacco product used ranged in age from 18-75, and their mean age was 33.37 ( $\mathrm{SD}=11.31$ ). Due to missing data, sample sizes differ for other study variables. 76.4\% were male, their average $\mathrm{BMI}$ was 30.31 (SD=8.98), their average blood pressure was $124.76(\mathrm{SD}=15.44)$ over $75.81(\mathrm{SD}=11.48)$, their mean bone density $\mathrm{T}$-score was $.07(\mathrm{SD}=1.34)$ with $26.9 \%$ having a T-score that indicated low bone density ( -1.0 or below), $68.3 \%$ reported that a family member uses tobacco, and $67.8 \%$ said they ate fruits and vegetables daily.

The majority of those who reported on type of tobacco product used (369 or $73.6 \%$ ) reported cigarette use only, while 53 people (10.6\%) reported dual or poly use of cigarettes and other tobacco products (cigars, pipe, tobacco chew), and 79 people (15.8\%) reported using only 
tobacco products other than cigarettes $(4.8 \%[n=24]$ cigars only, $10.2 \%[n=51]$ chewing tobacco only, and $0.8 \%[\mathrm{n}=4]$ pipe only).

Cigarette use only (total $n$ reported $=191$ )

Of those who used cigarettes and reported on the frequency of their use $(n=191)$, the majority $(75.8 \%)$ reported using cigarettes only. Of those who reported using cigarettes only, $79.6 \%(n=152)$ were daily smokers, and 39 (20.4\%) were nondaily smokers (see Table 2 ). Daily cigarette smokers' mean CPD was $10.08(\mathrm{SD}=9.50)$; 53.9\% $(\mathrm{n}=82)$ reported using less than 10 CPD, 18.4\% $(n=28)$ reported 10-19 CPD, $23.0 \%(n=35)$ reported 20-29 CPD, and 4.6\% $(n=7)$ reported 30 or more per day.

[Insert Table 1 about here]

\section{Bivariate Analyses}

As Table 1 shows, there were significant gender differences in types of tobacco product used $(\mathrm{p}=.000)$. Posthoc tests using the Bonferroni correction indicated that those who reported using only tobacco products other than cigarettes were significantly more likely to be male than those who used cigarettes only $\left(\chi^{2}(1)=16.151, p=.000\right)$, and those who reported dual or poly use were also significantly more likely to be male than those who used cigarettes only $\left(\chi^{2}(1)=4.195\right.$, $p=.041)$. Also, $6 \%$ of the women and $15.9 \%$ of the men reported using noncombustible tobacco products (chewing tobacco). Those who used chewing tobacco were significantly more likely to be male ( $\mathrm{p}=.006)$. The relationship between type of tobacco product used and frequency of use 
was also significant $(F[2,249]=6.98, \mathrm{p}=.001)$. There were no other statistically significant differences in study variables by type of tobacco products used.

Table 2 compares daily and nondaily smokers on each study variable. Given missing data, the sample sizes differ for each variable. As the table shows, daily and nondaily smokers did not differ on any study variable (age, gender, blood pressure, BMI, bone density, family member tobacco use, fruit and vegetable consumption).

[Insert Table 2 about here]

\section{Correlates of Cigarettes Smoked per Day}

The multiple regression reported in Table 3 is based on the 53 individuals who were daily smokers, reported CPD, and had complete data for all other study variables. CPD was measured as a continuous variable. Daily fruit and vegetable consumption was the only variable significantly associated with amount smoked (calculated as cigarettes per day [CPD]; $B=-0.40, p$ $=.003$ ), and explained $18 \%$ of the variance. Less than daily fruit and vegetable consumption was associated with higher CPD. The overall model was significant with an $\mathrm{R}^{2}$ (explained variance) of $30.1 \%$ in predicted amount smoked $(\mathrm{F}(8,44)=2.370, \mathrm{p}=.032)$ and a large effect size $\left(\mathrm{f}^{2}=.430\right.$; Cohen, 1988). Neither age, BMI, blood pressure, bone density, family member tobacco use, or gender was associated with the number of cigarettes smoked per day.

\section{[Insert Table 3 about here]}

The regression was re-run with only the variables that had significant bivariate correlations with amount smoked (bone density, fruits and vegetables). In this regression analysis 
$(n=77)$, both variables were significantly associated with CPD, and the overall model significantly $\left(\mathrm{R}^{2}=.214\right)$ predicted $\mathrm{CPD}(\mathrm{F}(2,74)=10.051, \mathrm{p}=.000)$ with a medium effect size $\left(\mathrm{f}^{2}=.272\right.$; Cohen, 1988). In this model, less than daily fruit and vegetable consumption was associated with higher CPD $(B=-0.376, \mathrm{p}=.000)$ and explained $15.2 \%$ of the variance. Not having low bone density was associated with higher CPD $(B=0.282, \mathrm{p}=.008)$, and explained $9.2 \%$ of the variance.

\section{Discussion}

Results show that of the Special Olympics athletes in the sample who used tobacco products, $73.6 \%$, reported using cigarettes only, while $10.6 \%$ reported dual or poly use of cigarettes and other tobacco products, and $15.8 \%$ reported using only one tobacco product other than cigarettes ( $4.8 \%$ cigars only, $10.2 \%$ chewing tobacco only, and $0.8 \%$ pipe only). This is quite different than the general U.S. adult population, in which $46.4 \%$ of tobacco users reported using cigarettes only, $40.5 \%$ reported dual or poly product use, and $20.6 \%$ reported using only one tobacco product other than cigarettes (Lee et al. 2014). Also in the general population, younger people are more likely to use noncombustible products, while there was no significant age difference by type of tobacco product used among the Special Olympics athletes (Richardson et al. 2014).

Similar to the general U.S. population, Special Olympics athletes who used tobacco reported high levels of any combustible tobacco product use (90.9\% [Agaku et al. 2015] and $89.8 \%$, respectively;), and both reported cigars and cigarettes as the most common dual usage 
(8.1\% [Lee at al. 2014] and 6.0\%, respectively). Also like the general population (Richardson et al. 2014), men in the Special Olympics sample were more likely than women to use noncombustible tobacco products (chewing tobacco).

Special Olympics athletes reported using tobacco at frequencies that ranged from once a year to 40 times per day. Of the athletes who reported using cigarettes, $79.6 \%$ were daily smokers. These results are higher than Haveman et al.'s European study (2011) in which 60.6\% of smokers reported daily use and they are slightly higher than the general U.S. population in which $76.8 \%$ of smokers report daily smoking (Jamal et al. 2015). Though Special Olympics athletes reported higher daily cigarette use than the general population, they reported a lower CPD rate (10.08) than daily cigarette users in the general U.S. population (13.8; Jamal et al. 2015). The majority of Special Olympics athletes who were daily smokers (53.9\%) reported smoking less than $10 \mathrm{CPD}$, while in the general population only $26.9 \%$ of daily smokers use less than 10 CPD (Jamal et al. 2015). In both the sample of Special Olympics athletes and the U.S. general population, the smallest percentage of daily smokers fall into the 30 or more CPD range (4.9\% vs 6.9\% [Jamal et al. 2015], respectively). Among Special Olympics athletes who reported using cigarettes, gender and age were not significantly associated with daily or nondaily cigarette smoking. This finding is inconsistent with European findings in which daily smoking was associated with older age (Haveman et al. 2011), and also unlike the general U.S. population in which females and those who are younger are more likely to be nondaily cigarette users ( $\mathrm{Li}$ et al. 2015; Schane et al. 2010; Schauer et al. 2014). 
Understanding tobacco use frequency has important implications for people with IDD. Research has found that nondaily smokers in the general population are less likely to receive medical advice to quit than daily smokers (Sacks et al. 2012; Schauer et al. 2014). This problem may be compounded for people with IDD who already face many barriers in accessing health care. Adults with IDD have difficulty finding healthcare providers willing to serve them. For this reason, some adults with IDD continue to use pediatricians as primary health care providers (Ward et al. 2010), and pediatricians may be less likely to question patients with IDD about tobacco use.

Several study limitations should be noted. While the CDC has identified the SOI Healthy Athletes database as one of the few available datasets to assess the health status of people with IDD (Campbell \& Edson 2009), the data used in this study only represents a subset of Special Olympics athletes and are not generalizible to all people with IDD in the United States. This sample may underestimate smoking prevalance as those in the sample have self-selected to participate in a sports-based organization, and may have healthier habits as it pertains to tobacco use. Also, because SOI health screenings began in 1997, it is possible that many in the sample have previously received tobacco education at prior SOI screenings, possibly already decreasing their tobacco use. Additionally, social desireability biases may have influenced Special Olympics athletes in self-reporting of tobacco use. In the general population many nondaily smokers do not identify as smokers, and they are likely to report themselves as nonsmokers when asked by health professionals, friends, and family (Schane et al. 2009). If these trends are true for 
individuals with IDD, it is possible that many nondaily users did not report any use at all. Also, since the data are cross sectional, causal relationships should not be inferred. Further, there was a significant amount of missing data on tobacco use frequency. Only $29.2 \%$ of athletes who reported tobacco use also reported frequency of use, limiting our study population. Finally, this study may have been limited by the lack of available data on other types of tobacco products such as e-cigarettes and hookah, which are now more popular than pipe tobacco (Agaku et al. 2014; Lee et al 2014), but which were not included in the data collection. E-cigarettes in particular are growing in popularity in the United States. While they are considered to have a much lower health risk than regular cigarettes, little data is available on the health effects of ecigarette use, and some e-cigarettes do produce high levels of formaldehyde, a known carcinogen.

Understanding trends in tobacco use prevalance, type, and frequency has important implications for health-related quality of life among people with IDD. Although people with IDD are less likely to use tobacco than the general population, study results suggest that people with IDD who smoke cigarettes are just as likely as smokers in the general U.S. population to smoke daily, potentially causing significant harm to health. Accessible easy-to-understand information about the health risks of tobacco use should be made available for people with IDD. Graphic (pictorial) warning labels have been shown to be more effective than written warning labels in discouraging smoking behaviors across populations, and can benefit individuals who have difficulty with reading or reading comprehension. (Rubinstein 2015). As of 2015, over 40 
countries have adopted World Health Organization recommendations for large graphic warning labels on tobacco product packaging (WHO 2015). However, the United States does not yet have graphic warning labels on cigarette packages due to successful efforts by tobacco companies to block their use (Kamyab et al. 2015; Rubinstein 2015). Advocating for the use of graphic warning labels could not only benefit people with IDD but could also benefit the entire U.S. population.

Additionally, there is a need to create accessible prevention and cessation programs that can effectively serve people with IDD. Prior literature on tobacco use among people with IDD is not sufficient to inform these efforts. Though the current study has limitations, it does suggest possible directions for such programs. The study found that men with IDD used tobacco products other than cigarettes at much higher rates than did women with IDD. Gender-specific prevention and intervention efforts focused on multiple types of tobacco product use may be beneficial for men with IDD. Additionally, although the number of cases used in the regression analyses were relatively small, power was adequate to detect relationships. Results showed that among daily smokers, higher numbers of cigarettes smoked per day was associated with eating fruits and vegetables less than daily. This may indicate that certain types of health behaviours are related to smoking behaviours. Individuals who smoke at highest rates may need education promoting overall healthy behaviours and may also need increased access to supports for healthy living. Further examination of factors associated with tobacco use and numbers of cigarettes smoked per day is necessary to inform targeted prevention and cessation efforts for this population. 
Though the data were limited, this study was able to examine some potentially important social and environemental factors, as well as individual tobacco use behaviours, that affect the health of people with IDD. This is a start in looking at the health behaviours of people with IDD, investigating the causes of the generally poorer health of people with IDD, and developing ways to improve their health.

\section{References}

Agaku I. T., King B. A., Husten C. G., Bunnell R., Ambrose B. K., Hu S. S., et al. (2014) Tobacco product use among adults_-United States, 2012-2013. MMWR Morb Mortal Wkly Rep 63, 542-547.

Berry-Kravis E. (2002) Epilepsy in fragile X syndrome. Developmental Medicine \& Child Neurology 44, 724-728.

Burtner A. P., Wakham M. D., McNeal D. R., \& Garvey T. P. (1995) Tobacco and the institutionalized mentally retarded: usage choices and ethical considerations. Special Care in Dentistry 15, 56-60.

Campbell N. \& Edson D. (2009) U.S. Surveillance of Health of People with Intellectual Disabilities (White paper). Retrieved from

This article is protected by copyright. All rights reserved. 
http://www.cdc.gov/ncbddd/disabilityandhealth/pdf/209537-a_idmeeting-shortversion12-14-09.pdf

Centers for Disease Control and Prevention. (2015a) About Adult BMI. Retrieved from http://www.cdc.gov/healthyweight/assessing/bmi/adult_bmi/

Centers for Disease Control and Prevention. (2015b) Smoking and tobacco use: Fast facts. Retrieved from http://www.cdc.gov/tobacco/data_statistics/fact_sheets/fast_facts/

Centers for Disease Control and Prevention. (2015c) Smoking and tobacco use: Health effects of cigarette smoking. Retrieved from http://www.cdc.gov/tobacco/data_statistics/fact_sheets/health_effects/effects_cig_smokin $\mathrm{g} /$

Centers for Disease Control and Prevention. (2015d) Tobacco-Related Mortality. Retrieved from http://www.cdc.gov/tobacco/data_statistics/fact_sheets/health_effects/tobacco_related_m ortality/

Cohen J. (1988) Statistical Power Analysis for the Behavioural Sciences (2nd ed.). Hillsdale, NJ: Lawrence Erlbaum Associates.

Emerson E. \& Hatton C. (2007) Poverty, socio-economic position, social capital and the health of children and adolescents with intellectual disabilities in Britain: a replication. Journal of Intellectual Disability Research 51, 866-874.

Emerson E. \& Turnbull, L. (2005) Self-reported smoking and alcohol use among adolescents with intellectual disabilities. Journal of Intellectual Disabilities $\mathbf{9}$,

This article is protected by copyright. All rights reserved. 
58-69.

Freeman S. B., Taft L. F., Dooley K. J., Allran K., Sherman S. L., Hassold T. J., et al. (1998) Population-based study of congenital heart defects in Down syndrome. American Journal of Medical Genetics 80, 213-217.

Haveman M., Perry J., Salvador-Carulla L., Walsh P. N., Kerr M., Van Schrojenstein Lantman-de Valk H., et al. (2011) Ageing and health status in adults with intellectual disabilities: Results of the European POMONA II study. Journal of Intellectual and Developmental Disability 36, 49-60.

Havercamp S. M. \& Scott, H. M. (2014) National health surveillance of adults with disabilities, adults with intellectual and developmental disabilities, and adults with no disabilities. Disability and Health Journal 8, 165-172.

Henderson C. M., Robinson L. M., Davidson P. W., Haveman M., Janicki M. P. \& Albertini G. (2008) Overweight status, obesity, and risk factors for coronary heart disease in adults with intellectual disability. Journal of Policy and Practice in Intellectual Disabilities $\mathbf{5}$, 174-177.

Heslop P., Blair P. S., Fleming P., Hoghton M., Marriott A. \& Russ L. (2014) The confidential inquiry into premature deaths of people with intellectual disabilities in the UK: a population-based study. The Lancet $\mathbf{3 8 3}, 889-895$.

This article is protected by copyright. All rights reserved. 
Jamal A., Homa D. M., O’Connor E., Babb S. D., Caraballo R. S. Singh, T., et al. (2015) Current Cigarette Smoking Among Adults-United States, 2005-2014. MMWR Morbidity and Mortality Weekly Report 64(, 1233-1240.

Janicki M. P., Davidson P. W., Henderson C. M., McCallion P., Taets J. D., Force, L. T., et al. (2002) Health characteristics and health services utilization in older adults with intellectual disability living in community residences. Journal of Intellectual Disability Research 46, 287-298.

Jones S. E., Kann L. \& Pechacek T. F. (2011) Cigarettes smoked per day among high school students in the US, 1991-2009. American Journal of Preventive Medicine 41, 297-299.

Kamyab K., Nonnemaker J. M. \& Farrelly M. C. (2015) Public support for graphic health warning labels in the US. American Journal of Preventive Medicine 48, 89-92.

Krahn G. L., Hammond L. \& Turner A. (2006) A cascade of disparities: health and health care access for people with intellectual disabilities. Mental Retardation and Developmental Disabilities Research Reviews 12, 70-82.

Lauer E. \& McCallion, P. (2015) Mortality of people with intellectual and developmental disabilities from select US state disability service systems and medical claims data. Journal of Applied Research in IntellectualDisabilities, .https://doi.org/10.1111/jar.12191

Lee Y. O., Hebert C. J., Nonnemaker J. M. \& Kim, A. E. (2014) Multiple tobacco product use among adults in the United States: cigarettes, cigars, electronic 
cigarettes, hookah, smokeless tobacco, and snus. Preventive Medicine 62, 14-19.

Li X., Holahan C.K. \& Holahan C.J. (2015) Sociodemographic and Psychological Characteristics of Very Light Smoking Among Women in Emerging Adulthood, National Survey of Drug Use and Health, 2011. Preventing Chronic Disease 12:140547. DOI: http://dx.doi.org/10.5888/pcd12.140547.

McGuire B. E., Daly P. \& Smyth F. (2007) Lifestyle and health behaviours of adults with an intellectual disability. Journal of Intellectual Disability Research 51, 497-510.

National Core Indicators. Chart Generator 2008-09, 2013-14. National Association of State Directors of Developmental Disabilities Services and Human Services Research Institute. Retrieved from http://www.nationalcoreindicators.org/charts/.

National Institutes of Health (NIH). (2015) Bone Mass Measurement: What the Numbers Mean. Retrieved from https://www.bones.nih.gov/sites/bones/files/bone-massmeasurement_0.pdf

Okuyemi K. S., Reitzel L. R. \& Fagan P. (2015) Interventions to Reduce TobaccoRelated Health Disparities. Nicotine \& Tobacco Research 17, 887-891.

O'Leary L., Cooper S. A. \& Hughes-McCormack L. (2018) Early death and causes of death of people with intellectual disabilities: A systematic review. Journal of Applied Research in Intellectual Disabilities 31, 325-342.

Pakhale S., Samet J., Folan P., Leone F. \& White A. (2016) The Case for Requiring 
Graphic Warning Labels on Smokeless Tobacco Product Packages. Annals of the American Thoracic Society 13, 329-333.

Pepper J. K., Emery S. L., Ribisl K. M., Rini C. M. \& Brewer N. T. (2015) How risky is it to use e-cigarettes? Smokers' beliefs about their health risks from using novel and traditional tobacco products. Journal of Behavioral Medicine 38, $318-326$.

Reichard A., Stolzle H. \& Fox M. H. (2011) Health disparities among adults with physical disabilities or cognitive limitations compared to individuals with no disabilities in the United States. Disability and Health Journal 4, 59-67.

Richardson A., Pearson J., Xiao H., Stalgaitis C. \& Vallone D. (2014) Prevalence, harm perceptions, and reasons for using noncombustible tobacco products among current and former smokers. American Journal of Public Health 104, 14371444.

Rimmer J. H., Braddock D. \& Marks B. (1995) Health characteristics and behaviours of adults with mental retardation residing in three living arrangements. Research in developmental disabilities 16, 489-499.

Rubinstein M. L. (2015) Scanning the brain for answers about effectiveness of graphic warning labels. Tobacco Control 24, 211-212.

Sacks R., Coady M. H. Mbamalu I. G., Johns M. \& Kansagra S. M. (2012) Exploring the next frontier for tobacco control: nondaily 
smoking among New York City adults. Journal of Environmental and Public Health 2012.

Schane R. E., Glantz S. A. \& Ling P. M. (2009) Social smoking: implications for public health, clinical practice, and intervention research. American Journal of Preventive Medicine 37, 124-131.

Schane R. E., Ling P. M. \& Glantz S. A. (2010) Health effects of light and intermittent smoking a review. Circulation 121, 1518-1522.

Schauer G. L., Malarcher A. M. \& Berg C. J. (2014) Differences in smoking and cessation characteristics among adult nondaily smokers in the United States: findings from the 2009-2010 National Adult Tobacco Survey. Nicotine \& Tobacco Research 16, 58-68.

Special Olympics International. (n.d.a) 2014 Reach Report. Retrieved from http://media.specialolympics.org/resources/reports/reachreports/2014_Special_Olympics Reach_Report.pdf

Special Olympics International. (n.d.b) Annual report 2014. Retrieved from http://media.specialolympics.org/resources/reports/annualreports/2014_AnnualRe port$\underline{\text { full.pdf }}$

Special Olympics International. (n.d.c) Special Olympics Research Overview. Retrieved from: http://media.specialolympics.org/resources/research/Special-Olympics$\underline{\text { Research-Overview.pdf }}$

This article is protected by copyright. All rights reserved. 
Special Olympics International. (2015a) Article 2: Special Olympics athletes. Retrieved from http://resources.specialolympics.org/Topics/General_Rules/Article_02.aspx Special Olympics International. (2015b) Special Olympics health athletes:

Healthy athletes 2014 data report. Washington DC: Special Olympics International. Retrieved from: http://media.specialolympics.org/resources/health/healthy-communities/HealthyCommunities-One-Pager-Health-and-Intellectual-Disability.pdf

Special Olympics International Research and Evaluation Department. (n.d.) Health \& intellectual disability. Retrieved from: http://media.specialolympics.org/resources/health/healthy-communities/HealthyCommunities-One-Pager-Health-and-Intellectual-Disability.pdf

Taylor N. S., Standen P. J., Cutajar P., Fox D. \& Wilson D. N. (2004) Smoking prevalence and knowledge of associated risks in adult attenders at day centres for people with learning disabilities. Journal of Intellectual Disability Research 48, 239-244.

Ward R. L., Nichols A. D. \& Freedman, R. I. (2010) Uncovering health care inequalities among adults with intellectual and developmental disabilities. Health \& Social Work 35, 280-290.

World Health Organization. (2010) Gender, women and the tobacco epidemic. Retrieved from http://www.who.int/tobacco/publications/gender/women_tob_epidemic/en/

This article is protected by copyright. All rights reserved. 
World Health Organization. (2015) WHO Report on the Global Tobacco Epidemic, 2015. Retrieved from:

http://apps.who.int/iris/bitstream/10665/178574/1/9789240694606_eng.pdf?ua=1 $\& u a=1$

This article is protected by copyright. All rights reserved. 
Table 1 Sample Characteristics and Bivariate Analyses of Factors Associated with Tobacco Product Type

\begin{tabular}{|c|c|c|c|c|c|}
\hline Variables & $\begin{array}{c}\stackrel{\text { All }}{100 \%} \\
(\mathrm{~N}=501)\end{array}$ & $\begin{array}{c}\text { Cigarettes Only } \\
73.65 \% \\
(\mathrm{~N}=369)\end{array}$ & $\begin{array}{c}\frac{\text { Dual Users }}{10.58 \%} \\
(\mathrm{~N}=53)\end{array}$ & $\begin{array}{c}\text { Other Product Only } \\
\begin{array}{c}15.77 \% \\
(\mathrm{~N}=79)\end{array}\end{array}$ & $p$ \\
\hline Mean Age $(\mathrm{n}=501)$ & $33.37(11.31)$ & $33.54(11.11)$ & $30.17(11.24)$ & $34.68(11.99)$ & .067 \\
\hline $\begin{array}{c}\text { Gender }(\mathrm{n}=495) \\
\text { Male }(\%)\end{array}$ & $76.4 \%$ & $71.6 \%$ & $84.9 \%$ & $93.4 \%$ & 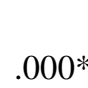 \\
\hline Mean BMI $(\mathrm{n}=445)$ & $30.31(8.98)$ & $30.17(8.92)$ & $31.70(8.80)$ & $29.99(9.36)$ & .515 \\
\hline Mean Systolic Blood Pressure $(\mathrm{n}=259)$ & $124.76(15.44)$ & $124.45(15.66)$ & $124.70(13.18)$ & $126.31(16.21)$ & .793 \\
\hline Mean Diastolic Blood Pressure $(\mathrm{n}=259)$ & 75.81(11.48). & 75.71(11.84) & $75.167(8.94)$ & $76.77(11.62)$ & .828 \\
\hline Mean Bone Density T-Score $(n=197)$ & $0.07(1.34)$ & $-0.08(1.32)$ & $-0.12(1.36)$ & $.03(1.46)$ & .912 \\
\hline Family Member Tobacco Use, yes $(\%)(\mathrm{n}=441)$ & $68.3 \%$ & $68.9 \%$ & $72.9 \%$ & $61.5 \%$ & .387 \\
\hline Daily Fruit/Vegetable Consumption, yes $(\%)(n=453)$ & $67.8 \%$ & $67.9 \%$ & $62.7 \%$ & $71.0 \%$ & .630 \\
\hline
\end{tabular}

( ): Standard deviation of the mean.

This article is protected by copyright. All rights reserved. 
* Denotes statistically significant group differences at $p<.05$ 
TABLE 2 Characteristics of Daily and Nondaily Cigarette Users

\begin{tabular}{|c|c|c|c|c|}
\hline Variable & $\begin{array}{l}\text { All } \\
191(100 \%)\end{array}$ & $\begin{array}{l}\text { Daily } \\
152(79.6 \%)\end{array}$ & $\begin{array}{l}\text { Nondaily } \\
39(20.4 \%)\end{array}$ & $p$ \\
\hline Mean Age $(n=191)$ & $33.66(10.91)$ & $33.64(10.34)$ & $33.72(11.67)$ & .969 \\
\hline \multicolumn{5}{|l|}{ Gender (n=191) } \\
\hline Male $(\%)$ & $71.7 \%$ & $71.7 \%$ & $74.4 \%$ & .683 \\
\hline Mean BMI $(\mathrm{n}=171)$ & $30.21(9.025)$ & $29.68(9.08)$ & $32.19(8.66)$ & .132 \\
\hline \multicolumn{5}{|l|}{ Mean Blood Pressure $(n=126)$} \\
\hline Systolic & $124.13(15.25)$ & $122.87(14.30)$ & $128.74(17.88)$ & .076 \\
\hline Diastolic & $75.71(10.35)$ & $75.64(10.25)$ & $75.96(10.89)$ & .885 \\
\hline Mean Bone Density T-Score $(\mathrm{n}=81)$ & $-.07(1.30)$ & $-0.10(1.14)$ & $0.05(1.12)$ & .630 \\
\hline \multicolumn{5}{|l|}{ Family Member Tobacco Use ( $\mathrm{n}=171)$} \\
\hline Yes $(\%)$ & $66.7 \%$ & $64.9 \%$ & $73.0 \%$ & .358 \\
\hline \multicolumn{5}{|l|}{ Daily Fruit and Vegetable $(n=174)$} \\
\hline Yes $(\%)$ & $69.5 \%$ & $66.9 \%$ & $80.0 \%$ & .132 \\
\hline
\end{tabular}

( ): Standard deviation of the mean. $p$ : Denotes group similarities/differences 
TABLE 3 Linear Regression Predicting Amount Smoked (CPD) Among Daily Smokers

\begin{tabular}{lcccc}
\hline Variables & B & SE & $\beta$ & $p$ \\
\hline Age & -0.54 & 1.29 & -0.06 & .677 \\
Gender & 0.10 & 2.75 & 0.01 & .971 \\
Body mass index & -1.14 & 1.44 & -0.11 & .432 \\
Systolic blood pressure & 1.23 & 1.68 & 0.11 & .468 \\
Diastolic blood pressure & 2.48 & 1.89 & 0.20 & .197 \\
Bone Density T-Score & 3.96 & 2.26 & 0.23 & .087 \\
Family Member Tobacco Use & -0.88 & 2.11 & -0.06 & .677 \\
Eating Fruits and Vegetables Daily & -6.84 & 2.20 & -0.40 & .003 \\
Constant & -17.732 & 19.562 & .370 & \\
\hline
\end{tabular}

te: $\mathrm{R}^{2}=.30 B=$ unstandardised regression coefficients. $S E=$ standard error. $\beta=$ Beta. 


\section{University Library}

\section{- M M I N E R VA A gateway to Melbourne's research publications}

Minerva Access is the Institutional Repository of The University of Melbourne

Author/s:

Eisenbaum, $\mathrm{E}$

Title:

Tobacco product use and smoking frequency among US adults with intellectual and developmental disabilities

Date:

2018-08-01

Citation:

Eisenbaum, E. (2018). Tobacco product use and smoking frequency among US adults with intellectual and developmental disabilities. [Abstract]. JOURNAL OF INTELLECTUAL DISABILITY RESEARCH, 62 (8), pp.709-718. https://doi.org/10.1111/jir.12507.

Persistent Link:

http://hdl.handle.net/11343/284170 